УДК 665.658:661.1836:541.128;547.21:549.67

НЕОКИСЛИТЕЛЬНАЯ КОНВЕРСИЯ ПРИРОДНОГО ГАЗА

В АРОМАТИЧЕСКИЕ УГЛЕВОДОРОДЫ

НА ВЫСОКОКРЕМНЕЗЁМНЫХ ЦЕОЛИТАХ

ТИПА ZSM-5, МОДИФИЦИРОВАННЫХ КАРБОНИЛАМИ

ВОЛЬФРАМА, ХРОМА И ВАНАДИЯ

\title{
NON-OXIDATIVE CONVERSION OF NATURAL GAS TO AROMATIC HYDROCARBONS ON HIGH-SILICON ZEOLITES OF ZSM-5 TYPE MODIFIED BY TUNGSTEN, CHROME AND VANADIUM
}

\section{Е.А. Ганбарова}

Бакинский государственный университет, Баку, Азербайджанская Республика

\section{Elnura A. Qanbarova}

\section{Baku State University, Baku, Republic of Azerbaijan e-mail: n_akhmed@mail.ru}

Аннотация. В интервале температур $650-750{ }^{\circ} \mathrm{C}$ на установке проточного типа при атмосферном давлении изучена неокислительная конверсия компонентов природного газа в ароматические углеводороды на высококремнезёмных цеолитах типа ZSM-5, модифицированных карбонилами вольфрама (2,0-6,0 \% масс.), хрома (0,5-2,0 \% масс.) и ванадия

(0,5-2,5 \% масс.). Модифицирование цеолита HZSM-5 карбонилом вольфрама оказывает промотирующее влияние на его ароматизирующую активность. Наиболее высокую активность проявляют монометаллические катализаторы, содержащие 4,0-5,0 \% масс. W. Основными жидкими продуктами являются бензол и нафталин, концентрация которых 
значительно зависит от температуры процесса и содержания вольфрама в HZSM-5. При $700{ }^{0} \mathrm{C}$ выход бензола составляет всего 7,4-8,2 \% масс. Установлено, что модифицирование катализатора 4 \% W/ HZSM-5 карбонилами хрома и ванадия на $50^{\circ} \mathrm{C}$ снижает температуру процесса и повышает его активность в образовании ароматических углеводородов. Наиболее высокое промотирующее влияние оказывает хром. При оптимальной концентрации хрома (1,0 \% масс.) в биметаллическом катализаторе Cr-W / HZSM-5 при температуре процесса $700{ }^{\circ} \mathrm{C}$ выход бензола возрастает до 13,6 \% масс. По выходу бензола (11,7 \% масс.) биметаллический катализатор V-W/HZSM-5 несколько уступает катализатору Cr-W / HZSM-5. Более высокий выход бензола (13,1 \% масс.) V-W / HZSM-5 в катализаторе достигается при содержании ванадия, равном $1,5 \%$ масс.

Показано, что изменение каталитических свойств HZSM-5 при их модифицировании карбонилами $\mathrm{W}, \mathrm{V}$ и $\mathrm{Cr}$ связано со снижением силы и концентрации сильных бренстедовских центров и образованием более сильных льюисовских кислотных центров, а также образованием хром- и ванадий-вольфрамовых наночастиц в каналах и на поверхности цеолита, что и является причиной возрастания ароматизирующей активности биметаллических катализаторов.

Abstract. In the temperature range of $650-750{ }^{\circ} \mathrm{C}$, at atmospheric pressure conditions, in the flow type equipment a non-oxidative conversion of natural gas components into aromatic hydrocarbons on high-silica ZSM-5 zeolites modified with tungsten carbonyls (2.0-6.0 \% wt.), Chromium (0.5-2.0\% wt.) and vanadium (0.5-2.5\% wt.) was studied. Modification of zeolite HZSM-5 with tungsten carbonyl has a promoting effect on its aromatizing activity. Monometallic catalysts, containing 4.0-5.0 \% wt. W, exhibit the highest activity. The main liquid products are benzene and naphthalene, whose concentration significantly depends on the process temperature and tungsten content in HZSM-5. At $700{ }^{\circ} \mathrm{C}$, the yield of benzene is just 7.4-8.2 \% wt. It was 
defined that the modification of the catalyst with $4 \% \mathrm{~W} / \mathrm{HZSM}-5$ by chromium and vanadium carbonyls at $50{ }^{\circ} \mathrm{C}$ reduces the process temperature and increases its activity in the formation of aromatic hydrocarbons. Chromium has the highest promotion effect. With an optimal concentration of chromium (1.0\% wt.) In the Cr-W / HZSM-5 bimetallic catalyst, at a process temperature of $700{ }^{\circ} \mathrm{C}$, the yield of benzene increases to $13.6 \%$ wt. For the yield of benzene (11.7\% wt.) the bimetallic catalyst V-W / HZSM-5 is somewhat inferior to the catalyst Cr-W / HZSM-5. A higher yield of benzene (13.1 \% wt.) in V-W / HZSM-5 catalyst is achieved with a vanadium content of $1.5 \mathrm{wt} . \%$.

It was shown that the change in the catalytic properties of HZSM-5 upon their modification with $\mathrm{W}, \mathrm{V}$, and $\mathrm{Cr}$ carbonyls is associated with a decrease in the strength and concentration of strong Bronsted centers and the formation of stronger Lewis acid centers, as well as the formation of chromium- and vanadium-tungsten nanoparticles in the channels and on the surface of the zeolite, which is the reason for the increase in the aroma activity of bimetallic catalysts.

Ключевые слова: высококремнезёмный цеолит ZSM-5; конверсия; выход; природный газ; бензол; нафталин; карбонилы; вольфрам; хром; ванадий

Key words: ZSM-5 high-silica zeolite; conversion; yield; natural gas; benzene; naphthalene; carbonyls; tungsten; chrome; vanadium

Рациональное использование природного газа является одной из приоритетных задач нефтехимии. В последние годы рассматриваются как прямые, так и косвенные конверсии природного газа в продукты нефтехимического синтеза $[1,2]$. Одним из перспективных направлений переработки компонентов природного газа является их прямое превращение в ароматические углеводороды на металлосодержащих катализаторах. Получаемые жидкие продукты можно использовать как 
высокооктановые добавки к бензинам или как ценное сырье для нефтехимической промышленности. Процесс ароматизации компонентов природного газа протекает в присутствии различных каталитических систем, среди которых наиболее эффективными оказались высококремнеземные цеолиты типа ZSM-5 [3-6]. Природа носителя, содержание активного металлического компонента, способ и условия приготовления катализатора являются основными факторами, определяющими его активность и селективность в процессе неокислительной конверсии компонентов природного газа. Одним из недостатков процесса неокислительной конверсии компонентов природного газа, протекающего при высоких температурах $(700-800$ C), является быстрая дезактивация катализаторов в результате интенсивного коксообразования. Для увеличения селективности и стабильности катализаторов их модифицируют различными металлами: Mo, W, La, Zr, $\mathrm{Fe}, \mathrm{Pt}$ и $\mathrm{Ga}[7,8]$. Обычно такие катализаторы готовят методом ионного обмена или пропитки цеолитного носителя водными растворами соответствующих металлов. Однако небольшая ионообменная ёмкость цеолитов ZSM-5 ограничивает количество вводимых металлов, а при пропитке трудно достичь равномерного распределения модификаторов по всему объёму цеолита. Поэтому метод твёрдофазного модифицирования цеолитного носителя с карбонилами металлов может оказаться более перспективным, так как в этом случае возможно стабилизировать металлы в каналах и полостях цеолитов и синтезировать металлоцеолитные системы в одну стадию без применения растворителей.

В данной статье приводятся результаты изучения влияния добавок карбонилов вольфрама, хрома и ванадия на кислотные и каталитические свойства цеолита ZSM-5 в процессе ароматизации компонентов природного газа. 


\section{Экспериментальная часть}

Для исследования использовали цеолит типа ZSM-5 с мольным отношением $\mathrm{SiO} / \mathrm{Al}_{2} \mathrm{O}_{3}=58$, который путем ионного обмена переводили в $\mathrm{NH}_{4}$-форму по методике, описанной в [6]. Н-форму цеолита получали термическим разложением $\mathrm{NH}_{4}$-формы при $550{ }^{\circ} \mathrm{C}$ в течение 4 ч. Н-форму цеолита модифицировали карбонилами вольфрама, хрома и ванадия методом твёрдофазного синтеза с последующим высушиванием в сушильном шкафу в течение 4 ч при $110^{\circ} \mathrm{C}$ и прокаливанием при $550{ }^{\circ} \mathrm{C}$ в течение 4 ч. Содержание модификаторов в катализаторе составляло (\% масс.): $\mathrm{W}-2,0-4,0 ; \mathrm{V}$ и $\mathrm{Cr}-0,5-2,5$. Кислотные свойства модифицированных цеолитов изучали методом термодесорбции аммиака [6]. В качестве исходного сырья использовали природный газ, \% масс.: метан - 84,1; этан - 4,5; пропан - 6,7; бутаны - 4,2; пентаны - 0,5. Конверсию природного газа проводили на установке проточного типа в кварцевом реакторе с загрузкой $5 \mathrm{~cm}^{3}$ катализатора при атмосферном давлении. Конверсию природного газа изучали при температуре $600-750{ }^{\circ} \mathrm{C}$ и объемной скорости подачи сырья $1000 ч^{-1}$. Продукты реакции анализировали хроматографическим методом [9].

\section{Результаты и их обсуждение}

На рисунке 1 приведены данные, полученные при превращении компонентов природного газа в присутствии немодифицированного цеолита, и данные о влиянии концентрации вольфрама на выход бензола и нафталина. 


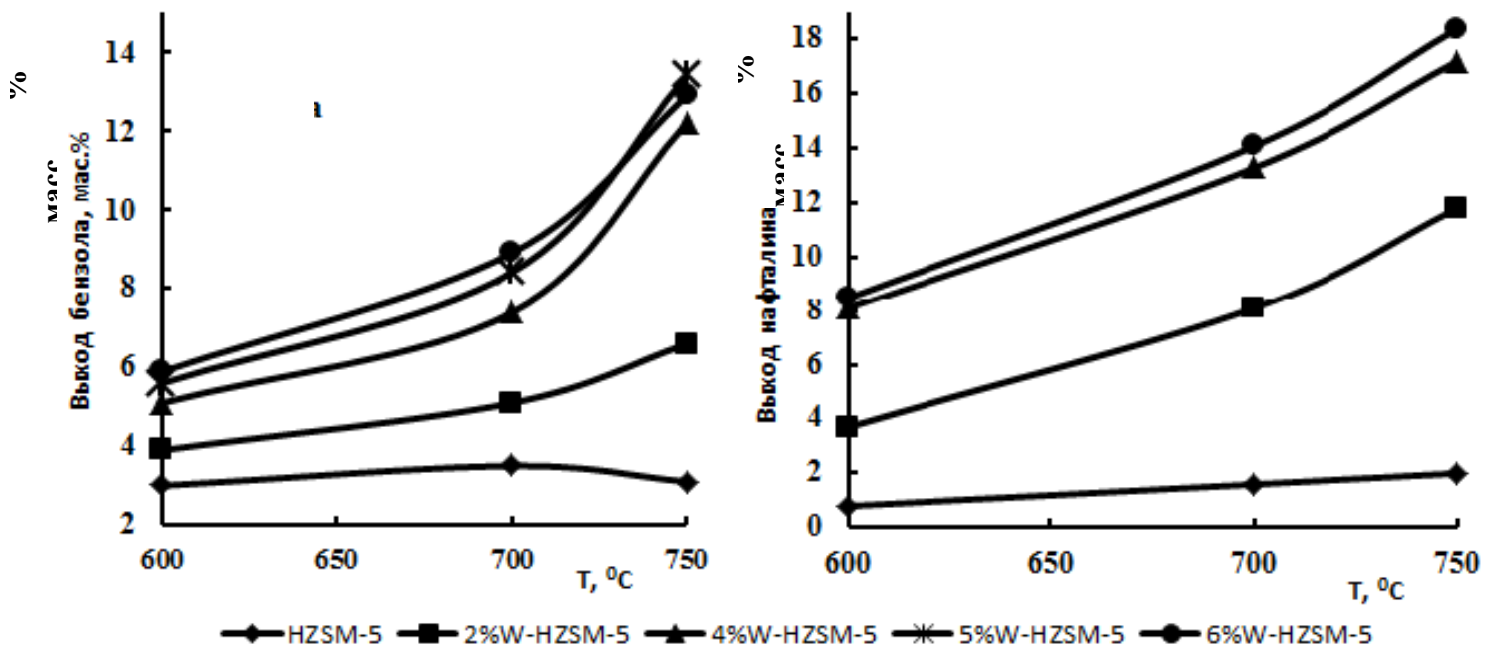

a)

б)

Рисунок 1. Зависимость выхода бензола (a) и нафталина (б) от температуры

Немодифицированный HZSM-5 проявляет невысокую каталитическую активность. В интервале температур $650-750{ }^{\circ} \mathrm{C}$ конверсия природного газа составляет 13,5-14,3\%, а выход ароматических углеводородов 3,8-5,1 \% масс. Модифицирование цеолита HZSM-5 карбонилом вольфрама оказывает промотирующее влияние на его активность и селективность. Основными жидкими продуктами являются бензол и нафталин, концентрация которых значительно зависит от температуры процесса и содержания вольфрама в HZSM-5. Введение в состав HZSM-5 $2,0 \%$ масс. вольфрама заметно повышает его активность. При $750{ }^{\circ} \mathrm{C}$ выход бензола возрастает с 3,1 до 6,6 \% масс. Увеличение содержания вольфрама до 5,0 \% масс. резко повышает активность катализатора. Образцы, содержащие 4,0 и 5,0 \% масс. вольфрама, проявляют близкую активность. На этих образцах уже при $700{ }^{\circ} \mathrm{C}$ выход бензола составляет 7,4-8,2 \% масс., а при $750{ }^{\circ} \mathrm{C}$ - выход бензола возрастает до 13,4 мас.\%. Дальнейшее увеличение содержание вольфрама (6,0 \% масс.) в составе HZSM-5 не приводит к росту выхода бензола (рисунок 2, a). На этом образце в интервале температур выход бензола составляет 5,9-13,1 \% масс. 


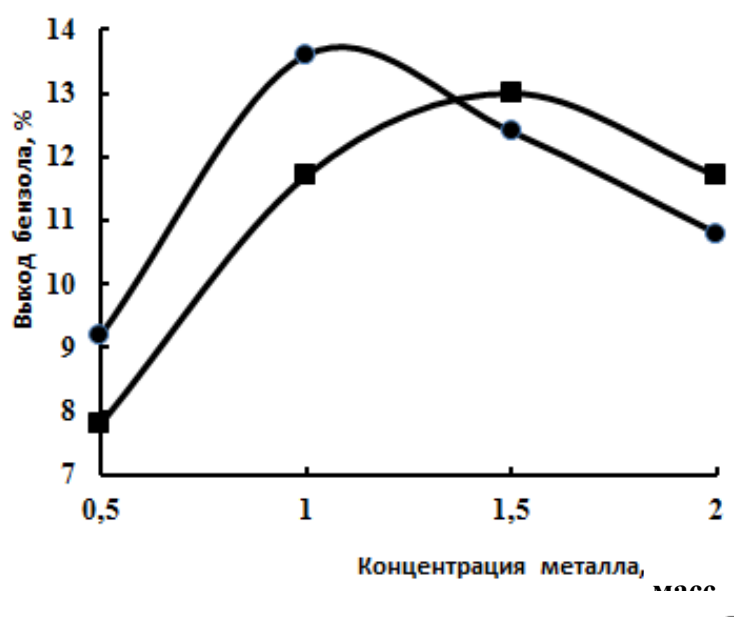

a)

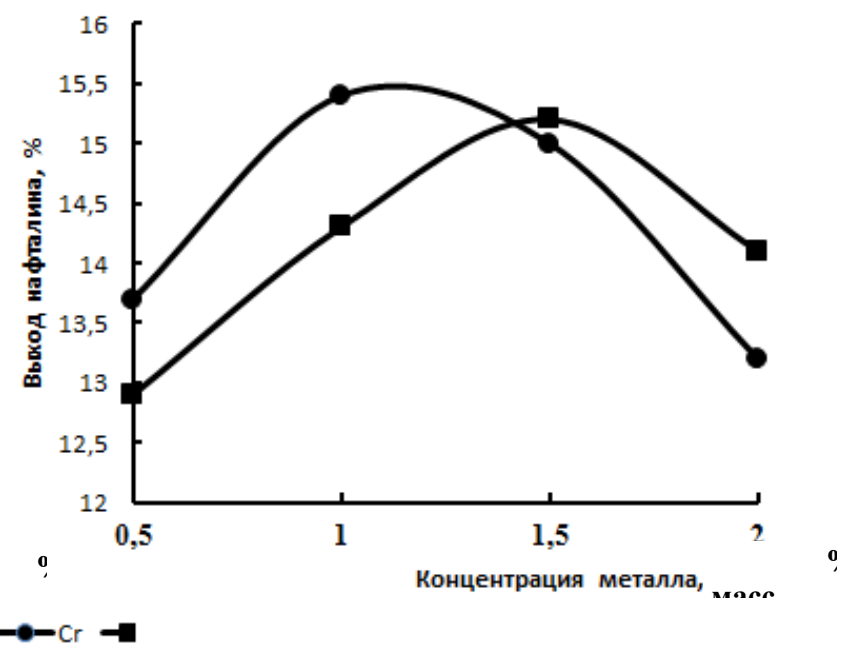

б)

Рисунок 2. Влияние концентрации модификаторов в составе биметаллического катализатора Me-4 \% W / HZSM-5 на выход бензола (a) и нафталина (б) при $700{ }^{\circ} \mathrm{C}$

В отличие от бензола во всем исследуемом интервале концентраций вольфрама наблюдается рост выхода нафталина (рисунок 2, б).

По выходу бензола (12,2-13,4 \% масс.) оптимальное содержание вольфрама в состав HZSM-5 составляет 4,0-5,0 \% масс.

Из анализа рисунка 2 видно, что модифицирование катализатора 4 \% W / HZSM-5 карбанилами хрома и ванадия значительно повышает его активность в образовании ароматических углеводородов. Наибольшее высокое промотирующее влияние оказывает хром.

В отличие от монометаллического катализатора $4 \%$ W/ HZSM-5, биметаллические Cr-W / HZSM-5 и V-W / HZSM-5 проявляют высокую активность при сравнительно низких температурах $\left(650-700{ }^{\circ} \mathrm{C}\right)$. Добавление к 4 \% W / HZSM-5 небольшого количества хрома (0,5% масс.) приводит к заметному росту выхода ароматических углеводородов. На этом образце при $700{ }^{\circ} \mathrm{C}$ выход бензола возрастает с 8,1 до 9,2 \% масс. Увеличение концентрации хрома в $4 \%$ W/HZSM-5 до 1,0 \% масс. приводит к резкому возрастанию выхода бензола до 13,6 \% масс. Дальнейшее увеличение содержания хрома в катализаторе (1,5-2,0 \% 
масс.) заметно снижает выход бензола (10,8-12,7 \% масс.), но увеличивает выход нафталина (с 12,9 до 15,1 \% масс.). По выходу бензола биметаллический катализатор V-W/HZSM-5 несколько уступает биметаллическому катализатору Cr-W/HZSM-5. При содержании модификаторов, равном 1,0% масс., выходы бензола на Cr-W / HZSM-5 и V-W / HZSM-5 составляют 13,6 и 11,7 \% масс. соответственно. Наиболее высокий Выход бензола (13,0 \% масс.) на катализаторе V-W / HZSM-5 достигается при содержании ванадия 1,5 \% масс. Дальнейшее увеличение содержания ванадия (2,0 \% масс.) заметно снижает его активность.

Различия в активности исходного и модифицированных катализаторов в конверсии природного газа в ароматические углеводороды, повидимому, связаны с природой активных центров. Результаты исследований кислотных свойств модифицированных катализаторов приведены в таблице 1. Видно, что наибольшей силой и концентрацией кислотных центров обладает HZSM-5. На HZSM-5 концентрация сильных кислотных центров составляет 548 мкмоль• $\Gamma^{-1}$, следовательно, в процессе превращения компонентов природного газа биметаллические $\mathrm{Cr}$ W / HZSM-5

V-W / HZSM-5 катализаторы проявляют более высокую каталитическую активность. Кроме того, по сравнению с монометаллическим катализатором высокий выход ароматических углеводородов на биметаллических катализаторах достигается при более низких температурах (650-700 C) проведения процесса. 
Таблица 1. Кислотные характеристики катализаторов

\begin{tabular}{|c|c|c|c|c|c|c|c|}
\hline \multirow[t]{2}{*}{ Катализатор } & \multicolumn{3}{|c|}{$\mathrm{T}_{\text {масс. }}$ формы, ${ }^{0} \mathrm{C}$} & \multicolumn{4}{|c|}{$\begin{array}{c}\text { Концентрация кислотных } \\
\text { центров, мкмоль·-Г⿸厂 }\end{array}$} \\
\hline & $\mathrm{T}_{\mathrm{I}}$ & $\mathrm{T}_{\text {II }}$ & $\mathrm{T}_{\text {III }}$ & $\mathrm{C}_{\mathrm{I}}$ & $\mathrm{C}_{\mathrm{II}}$ & $\mathrm{C}_{\mathrm{III}}$ & $\mathrm{C}_{\text {сум. }}$ \\
\hline HZSM-5 & 198 & 418 & - & 625 & 548 & - & 1173 \\
\hline $2 \% \mathrm{~W} / \mathrm{HZSM}-5$ & 196 & 367 & - & 394 & 379 & - & 773 \\
\hline $4 \% \mathrm{~W} / \mathrm{HZSM}-5$ & 192 & 321 & - & 336 & 208 & - & 544 \\
\hline $0,5 \% \mathrm{Cr}-4 \% \mathrm{~W} / \mathrm{HZSM}-5$ & 190 & 317 & - & 329 & 202 & - & 531 \\
\hline $1,0 \% \mathrm{Cr}-4 \% \mathrm{~W} / \mathrm{HZSM}-5$ & 188 & 312 & 435 & 324 & 198 & 40 & 562 \\
\hline $2,0 \% \mathrm{Cr}-4 \% \mathrm{~W} / \mathrm{HZSM}-5$ & 188 & 303 & 440 & 318 & 192 & 55 & 567 \\
\hline $1,0 \% \mathrm{~V}-4 \% \mathrm{~W} / \mathrm{HZSM}-5$ & 190 & 318 & 430 & 327 & 204 & 45 & 576 \\
\hline $2,0 \% \mathrm{~V}-4 \% \mathrm{~W} / \mathrm{HZSM}-5$ & 190 & 309 & 450 & 322 & 196 & 60 & 578 \\
\hline \multicolumn{8}{|c|}{$\begin{array}{l}\text { Примечания: } \\
\mathrm{T}_{\mathrm{I} ;} \mathrm{T}_{\mathrm{II}} \mathrm{T}_{\mathrm{III}}-\text { температуры максимумов пиков для форм I, II, III; } \\
\mathrm{C}_{\mathrm{I}} \mathrm{C}_{\mathrm{II}} \mathrm{C}_{\mathrm{III}}-\text { концентрации кислотных центров в формах и суммарная соответственно I, } \\
\text { II, III. }\end{array}$} \\
\hline
\end{tabular}

В процессе модифицирования цеолита HZSM-5 вольфрамом происходит снижение силы и концентрации кислотных центров обоих типов, что свидетельствует о взаимодействии средних и сильных бренстедовских кислотных центров цеолита с вольфрамом. Введение хрома и ванадия в состав катализатора $4 \%$ W/ HZSM-5 приводит к изменению его кислотных характеристик, что особенно проявляется при содержании $\mathrm{Cr}$ и $\mathrm{V}$, равном 1,0-2,0 \% масс. В ТД-спектрах образцов $(1,0$ 2,0 \% масс. Cr или V / 4 \% W / HZSM-5) наблюдается появление третьего пика с высокой энергией удерживания аммиака. Концентрация кислотных центров высокотемпературной формы больше на образцах, содержащих 2,0 \% масс. модификатора. Это указывает на возможное взаимодействие вольфрама с хромом и ванадием с образованием хром- и ванадийвольфрамовых наночастиц различного состава, что и является причиной возрастания активности W/ HZSM-5 в результате его модифицирования карбонилами хрома и ванадия. 


\section{Выводы}

Таким образом, модифицирование цеолита $4 \% \mathrm{~W} / \mathrm{HZSM}-5$ карбонилами хрома и ванадия с последующим их прокаливанием при $550{ }^{\circ} \mathrm{C}$ приводит к снижению сильных бренстедовских кислотных центров и образованию новых более сильных льюисовских кислотных центров и хром-, ванадий-вольфрамовых наночастиц внутри и на внешней поверхности цеолита, что и приводит к возрастанию его ароматизирующей активности в процессе превращения компонентов природного газа.

\section{Список используемых источников}

1. Восмериков А.В., Кудряшов С.В. Перспективные технологии химической переработки попутного нефтяного газа в ценные жидкие продукты // Газохимия. 2010. № 2 (12). С. 62-67.

2. Васильева Н.А., Буянов Р.А. Генерация радикалов при пиролизе нундекана на $\mathrm{BaCl}_{2}$ и дефектных оксидах магния // Химия в интересах устойчивого развития. 2004. Т. 12. № 6. С. 661-668.

3. Восмериков В.Н., Восмерикова А.В. Прямое превращение природного газа в жидкость на модифицированных цеолитах // Газохимия. № 3 (13). 2010. C. 54-56.

4. Савицкий С.Ю. Разработка галлий скандий промотированного цеолитового катализатора конверсии углеводородов попутного нефтяного газа // Электронный научный журнал «Нефтегазовое дело». 2012. № 2. C. 330-335. URL: http://ogbus.ru/files/ogbus/authors/Savitskii/Savitskii_1.pdf (дата обращения: 17.08.2019).

5. Aboul-Gheit A.K., Awadallah A.E., El-Kossy S.M., Mahmou A.-L. H. Effect of Pd or Ir on the Catalytic Performance of Mo/H-ZSM-5 during the NonOxidative Conversion of Natural Gas to Petrochemicals // Journal of Natural Gas Chemistry. 2008. No. 17 (4). P. 337-343. 
6. Ганбарова Е.А., Алиев Т.А., Мамедов С.Э., Махмудова Н.И. Превращение природного газа на высококремнезёмном цеолите типа ЦВМ, модифицированном нанопорошками циркония и молибдена // Проблемы химии. 2015. № 4. С. 388-392.

7. Цыганова Е.И., Шекунова В.М, Александров Ю.А., Филофеев С.В., Лелеков В.Е. Каталитический пиролиз лёгких алканов в присутствии металлов шестой группы // Вестник Южно-Уральского государственного университета. Серия: Химия. 2016. Т. 8. № 3. С. 19-27. DOI: 10.14529/chem160303.

8. Цыганова Е.И., Шекунова В.М., Александров Ю.А., Филофеев С.В., Лелеков В.Е. Влияние металлов восьмой группы на каталитический пиролиз низших алканов // Журнал общей химии. 2015. Т. 85. № 1. С. 1925. DOI: $10.1134 / \mathrm{S} 1070363215010041$.

9. Qanbarova E.A., Babayeva T.A., Akhmedova N.F., Mirzaliyeva S.E., Mamedov S.E. The Transformation of Natural Gas and Methanol on Bimetallic Zeolite Catalysts // Journal of Environmental Science, Computer Science and Engineering \& Technology. 2019. Vol. 8. No. 2. P. 160-166. DOI: 10.24214/jecet.A.8.2.16066.

\section{References}

1. Vosmerikov A.V., Kudryashov S.V. Perspektivnye tekhnologii khimicheskoi pererabotki poputnogo neftyanogo gaza $\mathrm{v}$ tsennye zhidkie produkty [Promising Technologies of Chemical Processing of Associated Petroleum Gas into Valuable Liquid Products]. Gazokhimiya - Gas Chemistry, 2010, No. 2 (12), pp. 62-67. [in Russian].

2. Vasil'eva N.A., Buyanov R.A. Generatsiya radikalov pri pirolize nundekana na $\mathrm{BaCl} 2$ i defektnykh oksidakh magniya [Radical Generation during Pyrolysis of n-Undecane on $\mathrm{BaCl} 2$ and Imperfect Magnesium Oxides]. Khimiya $v$ interesakh ustoichivogo razvitiya - Chemistry for Sustainable Development, 2004, Vol. 12, No. 6, pp. 661-668. [in Russian]. 
3. Vosmerikov B.H., Vosmerikova A.B. Pryamoe prevrashchenie prirodnogo gaza $\mathrm{v}$ zhidkost' na modifitsirovannykh tseolitakh [Direct Conversion of Natural Gas to Liquid on Modified Zeolites]. Gazokhimiya - Gas Chemistry, No. 3 (13), 2010, pp. 54-56. [in Russian].

4. Savitskii S.Yu. Razrabotka gallii skandii promotirovannogo tseolitovogo katalizatora konversii uglevodorodov poputnogo neftyanogo gaza [Development of Gallium, Scandium Promoted Zeolite Catalyst for Associated Petroleum Gas Processing]. Elektronnyi nauchnyi zhurnal «Neftegazovoe delo»-Electronic Scientific Journal «Oil and Gas Business», 2012, No. 2, pp. 330-335. URL: http://ogbus.ru/files/ogbus/authors/Savitskii/Savitskii_1.pdf (accessed 17.08.2019). [in Russian].

5. Aboul-Gheit A.K., Awadallah A.E., El-Kossy S.M., Mahmou A.-L. H. Effect of Pd or Ir on the Catalytic Performance of Mo/H-ZSM-5 during the NonOxidative Conversion of Natural Gas to Petrochemicals. Journal of Natural Gas Chemistry, 2008, No. 17 (4), pp. 337-343.

6. Ganbarova E.A., Aliev T.A., Mamedov S.E., Makhmudova N.I. Prevrashchenie prirodnogo gaza na vysokokremnezemnom tseolite tipa TsVM, modifitsirovannom nanoporoshkami tsirkoniya i molibdena [Transformation of Natural Gas on the Basis of High-Silica Zsm Type Zeolite Modified by Zr and Mo Nano-Powders]. Zhurnal problemy khimii - Chemical Problems, 2015, No. 4, pp. 388-392.

7. Tsyganova E.I., Shekunova V.M, Aleksandrov Yu.A., Filofeev S.V., Lelekov V.E. Kataliticheskii piroliz legkikh alkanov v prisutstvii metallov shestoi gruppy [Effect of the VI Group Metals on the Catalytic Pyrolysis of Lover Alkanes.]. Vestnik Yuzhno-Ural'skogo gosudarstvennogo universiteta. Seriya: Khimiya - Bulletin of the South Ural State University. Ser. Chemistry, 2016, Vol. 8, No. 3, pp. 19-27. DOI: 10.14529/chem160303. 
8. Tsyganova E.I., Shekunova V.M., Aleksandrov Yu.A., Filofeev S.V., Lelekov V.E. Vliyanie metallov vos'moi gruppy na kataliticheskii piroliz nizshikh alkanov [Effect of the VIII Group Metals on the Catalytic Pyrolysis of Lower Alkanes]. Zhurnal obshchei khimii - Russian Journal of General Chemistry, 2015, Vol. 85, No. 1, pp. 19-25. DOI: 10.1134/S1070363215010041.

9. Qanbarova E.A., Babayeva T.A., Akhmedova N.F., Mirzaliyeva S.E., Mamedov S.E. The Transformation of Natural Gas and Methanol on Bimetallic Zeolite Catalysts. Journal of Environmental Science, Computer Science and Engineering \& Technology, 2019, Vol. 8, No. 2, pp. 160-166. DOI: 10.24214/jecet.A.8.2.16066.

\section{Сведения об авторе}

About the author

Ганбарова Ельнура Абульфаз гызы, диссертант кафедры «Физическая и коллоидная химия», Бакинский государственный университет, г. Баку, Азербайджанская Республика

Elnura A. Qanbarova, Ph. Student of Physical and Colloidal Chemistry Department, Baku State University, Baku, Republic of Azerbaijan e-mail: n_akhmed@mail.ru 